\title{
Commentary
}

\section{Resilience: Easy to use but hard to define}

\author{
Isla H. Myers-Smith, Sarah A. Trefry, and Vanessa J. Swarbrick
}

Isla H. Myers-Smith (imyerssmith@ualberta.ca), Biological Sciences Department, University of Alberta, Edmonton, AB, Canada T6G $2 E 9$

Sarah A. Trefry (s.trefry@unb.ca), Department of Biology, University of New Brunswick, Fredericton, NB, Canada E3B $5 A 3$

Vanessa J. Swarbrick (vanessa.swarbrick@gmail.com), Department of Biology, University of Regina, Regina, SK, Canada S4S OA2

\begin{abstract}
First conceptualized in the 1970 s, resilience has become a popular term in the ecological literature, used in the title, abstract, or keywords of approximately $1 \%$ of papers identified by ISI Web of Science in the field of environmental sciences and ecology in 2011. However, many papers make only passing reference to the term and do not explain what resilience means in the context of their study system, despite there being a number of possible definitions. In an attempt to determine how resilience is being used in ecological studies, we surveyed 234 papers published between 2004 and 2011 that were identified under the topic "resilience" by ISI Web of Science. Of these, $38 \%$ used the word resilience fewer than three times (often in the abstract or keyword list), $66 \%$ did not define the term, and $71 \%$ did not provide a citation to the resilience literature. Studies that defined resilience most often discussed it as pertaining to an entire ecosystem under continuous rather than discrete disturbance. Given the complex nature of this concept, we believe that care should be taken to properly describe what is meant by the term resilience in ecological studies.
\end{abstract}

Keywords: disturbance, ecology, ecological definitions, stability, resilience.

\section{Introduction}

Many ecological terms, such as succession, community, disturbance, competition, and resilience, have arisen from vernacular origins (Pickett et al. 2004). While the meanings of most of these terms have become more consistently defined over time, many definitions of resilience persist (Cumming et al. 2005, Botton et al. 2006). In their 1997 literature review, Grimm and Wissel found 17 different definitions of the term resilience. As graduate students in an Advanced Ecology course at the University of Alberta, we were struck by the continued lack of consensus in definitions of resilience (Table 1), despite a growing popularity for the term in the ecological literature (Figure 1). In this study, we assess the current use of resilience in the ecological literature and question how the term can be better employed. We posed the following questions:

1. What types of studies refer to resilience? Is there a pattern of its use in the ecological literature?

2. How frequently do studies use resilience or provide a definition for the term? What are the most commonly used definitions?

Though we are not the first to discuss these issues, we hope that by posing these questions, we will promote a better understanding of the current uses, and greater precision in the use of resilience in the field of ecology. 
Table 1. The number of citations for the top five authors cited for definitions of resilience in our literature survey calculated using Web of Science (ISI Web of Knowledge, Thompson Corporation). Definitions are quoted directly from the original text or abridged. Asterisks indicate book chapters where citations were enumerated using Google Scholar (citations are prior to July 2012). These are over-estimates as they include sources other than the primary literature. Folke et al. 2004 and Folke 2006 are also cited frequently, however, these manuscripts refer to the Walker and Holling definitions in their text.

\begin{tabular}{|c|c|c|c|}
\hline Author & Definition & \# Citations & Reference \\
\hline \multirow[t]{2}{*}{ 1. Holling } & \multirow{2}{*}{$\begin{array}{l}\text { A measure of the persistence of systems and of their ability } \\
\text { to absorb change and disturbance and still maintain the same } \\
\text { relationships between populations or state variables. }\end{array}$} & 1743 & Holling 1973 \\
\hline & & $294^{*}$ & Holling 1996 \\
\hline 2. Gunderson & $\begin{array}{l}\text { Property of an ecosystem that describes the change in } \\
\text { stability (or return time) and resilience (the width of the } \\
\text { stability domain). }\end{array}$ & 281 & $\begin{array}{l}\text { Gunderson } \\
2000\end{array}$ \\
\hline 3. Walker & $\begin{array}{l}\text { Resilience (the capacity of a system to absorb disturbance } \\
\text { and reorganize while undergoing change so as to still retain } \\
\text { essentially the same function, structure, identity, and feed- } \\
\text { backs). Resilience has four components-latitude, resist- } \\
\text { ance, precariousness, and panarchy-most readily portrayed } \\
\text { using the metaphor of a stability landscape. }\end{array}$ & 269 & $\begin{array}{l}\text { Walker et al. } \\
2004\end{array}$ \\
\hline \multirow[t]{2}{*}{ 4. Carpenter } & $\begin{array}{l}\text { The rate at which a system returns to equilibrium after dis- } \\
\text { turbance. }\end{array}$ & 90 & $\begin{array}{l}\text { Carpenter et } \\
\text { al. } 1992\end{array}$ \\
\hline & $\begin{array}{l}\text { The magnitude of disturbance that can be tolerated before a } \\
\text { socio-ecological system moves to a difference region of a } \\
\text { state space controlled by a different set of processes, includ- } \\
\text { ing the degree to which the system is capable of self- } \\
\text { organization, and how much it expresses a capacity for } \\
\text { learning and adaptation. }\end{array}$ & 341 & $\begin{array}{l}\text { Carpenter et } \\
\text { al. } 2001\end{array}$ \\
\hline 5. Pimm & $\begin{array}{l}\text { How fast a variable that has been displaced from equilibrium } \\
\text { returns to it. Resilience could be estimated by a return time: } \\
\text { the amount of time taken for the displacement to decay to } \\
\text { some specified fraction of its initial value. }\end{array}$ & $1659 *$ & Pimm 1991 \\
\hline
\end{tabular}

\section{Methods}

We conducted searches of Web of Science (ISI Web of Knowledge, Thompson Corporation) for the terms TS(topic)='resilience' and 'ecology', published from 2004 to 2011. We excluded all papers from nonecological journals (e.g., Computational Biology and Chemistry, Environmental Geology, Environment and Development Economics, and Journal of Archaeological Science), and ended with 234 relevant studies. We classified each article as to type (review, mensurative experiment, manipulative experiment, modelling study, meta-analysis), sub-discipline (basic, applied, social, theoretical), study ecosystem (terrestrial, marine, freshwater, urban, wetland, soil), study organism (animal, plant, coral, microbe, fungi), and disturbance (press or pulse). We also classified the definition of resilience, when one was provided, as either quantitative or qualitative based on whether the explanatory term used in the definition was quantifiable. For example, if an author defined resilience using the term 'ability' or 'capacity', we classified it as a qualitative definition; if the term 'rate', 'speed', or 'magnitude' was used, we considered it to be quantitative. We quantified the number of times that the ecological term resilience was used by categorizing the number of uses in the component sections of the paper (title, abstract, keywords and body). We did not include non-ecological uses of the term.

\section{Results}

What types of studies refer to resilience? Is there a pattern of its use in the ecological literature?

We found no particular pattern in the use of resilience in the ecological literature. Our survey contained a broad range of articles (Figure 2A) from basic, applied, social 


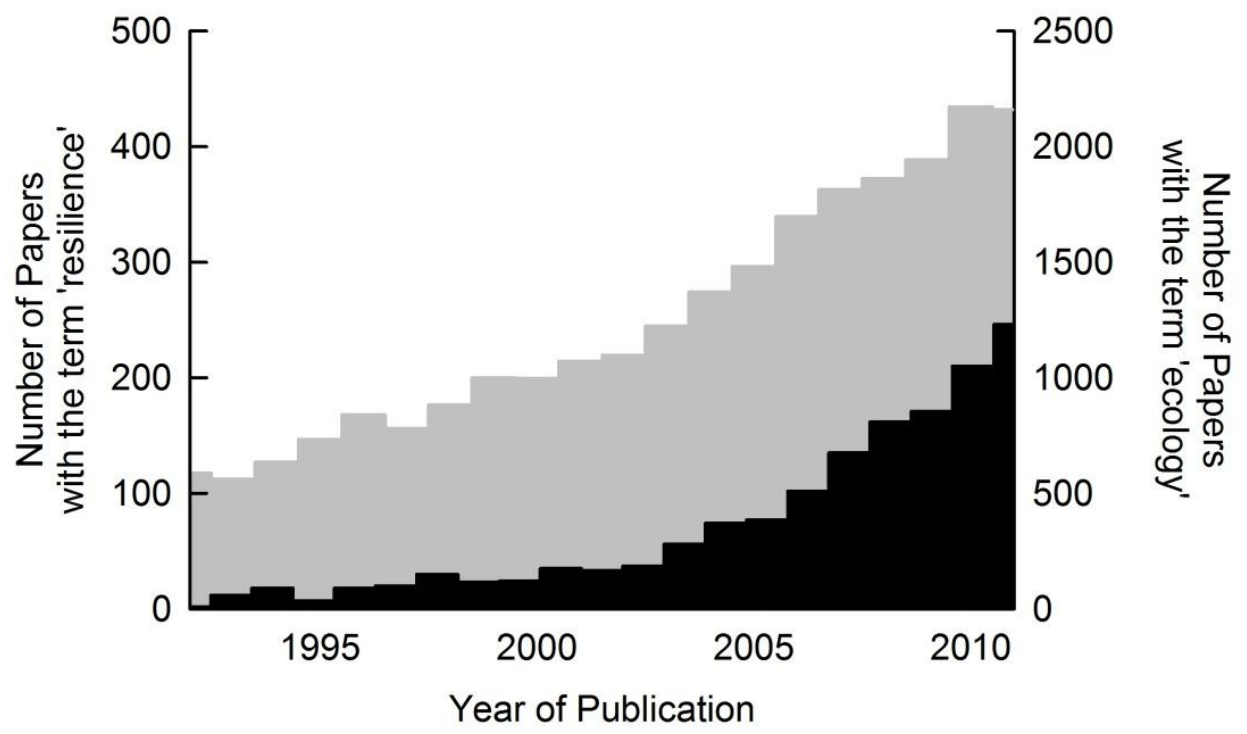

Figure 1. Change in frequency of the term resilience in the ecology literature over time (black bars) calculated using a Web of Science (ISI Web of Knowledge, Thompson Corporation) search for the term 'resilience' in the subject category 'Ecology' $(\mathrm{N}=1748$ papers). Grey bars represent the rate of increase in ecology publications by searching for the term 'ecology' in the subject category ( $\mathrm{N}=28116$ papers). The rate of exponential increase is 0.17 for the trend in papers flagged by the term 'resilience' and 0.07 for papers flagged by the term 'ecology'.

and theoretical disciplines (Figure 2B) and covering terrestrial, freshwater and marine ecosystems (Figure $2 \mathrm{C})$. The disturbances under investigation varied from press (continual) disturbances, such as climate change, to pulse (discrete) disturbances, such as nutrient additions or forest fires (Figure 2E).

How frequently do studies define the term and what are the most commonly used definitions?

In our literature review, $38 \%$ of studies used the word resilience fewer than three times (often in the abstract or keyword list). Of the broad range of papers sampled, $66 \%$ did not define and $71 \%$ did not cite a definition for resilience (Figure 2F). When definitions were given, approximately two thirds of the time they were qualitative versus quantitative, using terms like "ability" or "capacity", rather than "rate" or "amount" (Figure 3). Seventeen different explanatory words were used in resilience definitions (Figure $2 \mathrm{H}$ ) including ability, amount, capacity, characteristic, degree, distance, magnitude, persistence, potential, property, rate, recovery, return-time, shift, size, speed and time. Of those that provided a reference, Holling's (1973) paper was cited most frequently (Figure 3). For papers that cited Holling, eight different explanatory words, qualitative and quantitative, were used in the definitions provided for resilience (Figure 3). For papers that described a disturbance, $44 \%$ referred to press (ongoing) rather than pulse or multiple disturbances (Figure 3).

\section{Discussion}

Over one third of papers surveyed used the term resilience fewer than three times, and nearly two thirds did not provide a definition of or a citation for the term. If this term was consistently defined in the ecological literature these numbers would not necessarily be concerning; however, we found many different resilience definitions (Figure 3). Because resilience could be used as a passing reference in studies that are investigating other subjects, we assessed the number of times resilience was used in papers that provided an ecological definition or citation for the term (Figure 4). We found that $13 \%$ of papers provided a definition or citation and used resilience fewer than three times in the body text while referring to the term in the title, abstract or keywords. The high frequency of this sort of usage (Figure 4) indicates that many authors perceived this ecological term to be of importance to their study; however, they are not explaining the relevance of the term to their work in detail.

We found a variety of definitions of the term resilience in our literature survey (Table 1, Figure 2), 
A. Type of Article

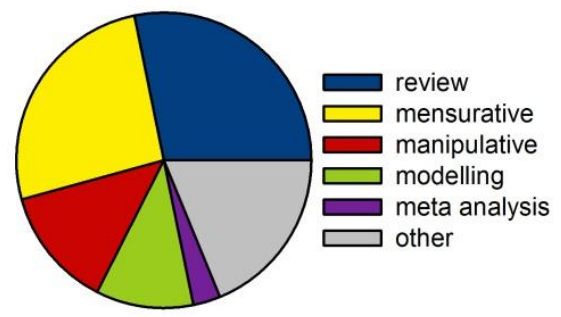

C. Type of Ecosystem

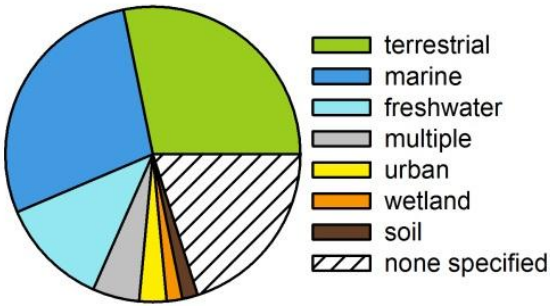

E. Type of Disturbance

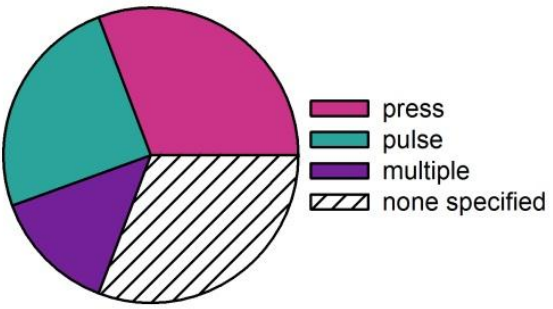

G. Definition

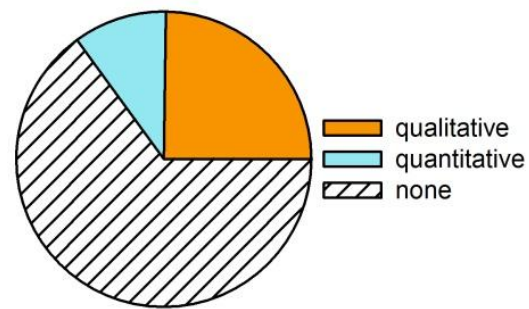

B. Discipline

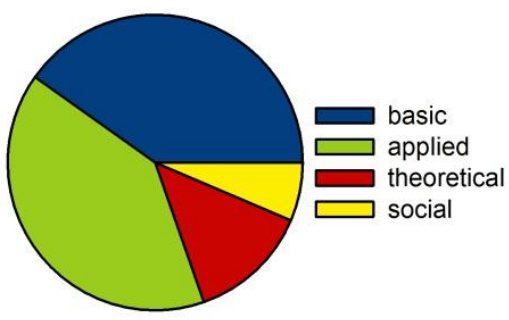

D. Type of Organism

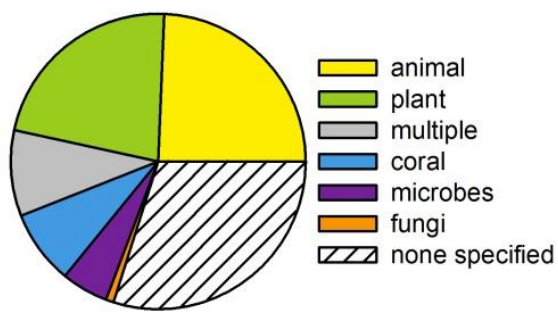

F. Citation

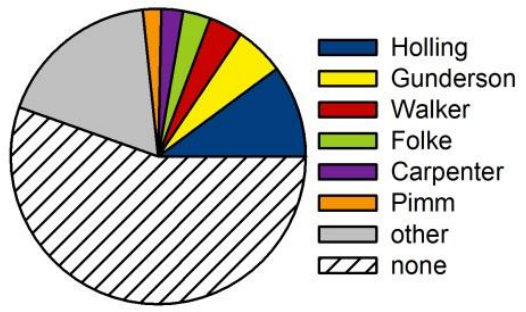

H. Terminology Used

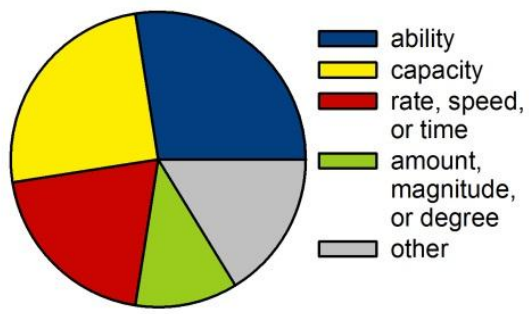

Figure 2. Characteristics of the papers reviewed, including the type of article (A), discipline (B), ecosystem (C), organism (D), and disturbance (E) under investigation, lead author cited (F), and how each paper defines resilience $(\mathrm{G}, \mathrm{H})$. Most papers gave no definition of the term resilience and there was no clear trend of usage of the term by sub-discipline or field of investigation.

with $25 \%$ of studies providing a qualitative and $10 \%$ a quantitative definition of the term. For definitions including the most commonly provided citation, Holling
(1973), nine different explanatory words were used (Figure 3) and this mismatch between the definition stated and the citation given could exist for other of the 


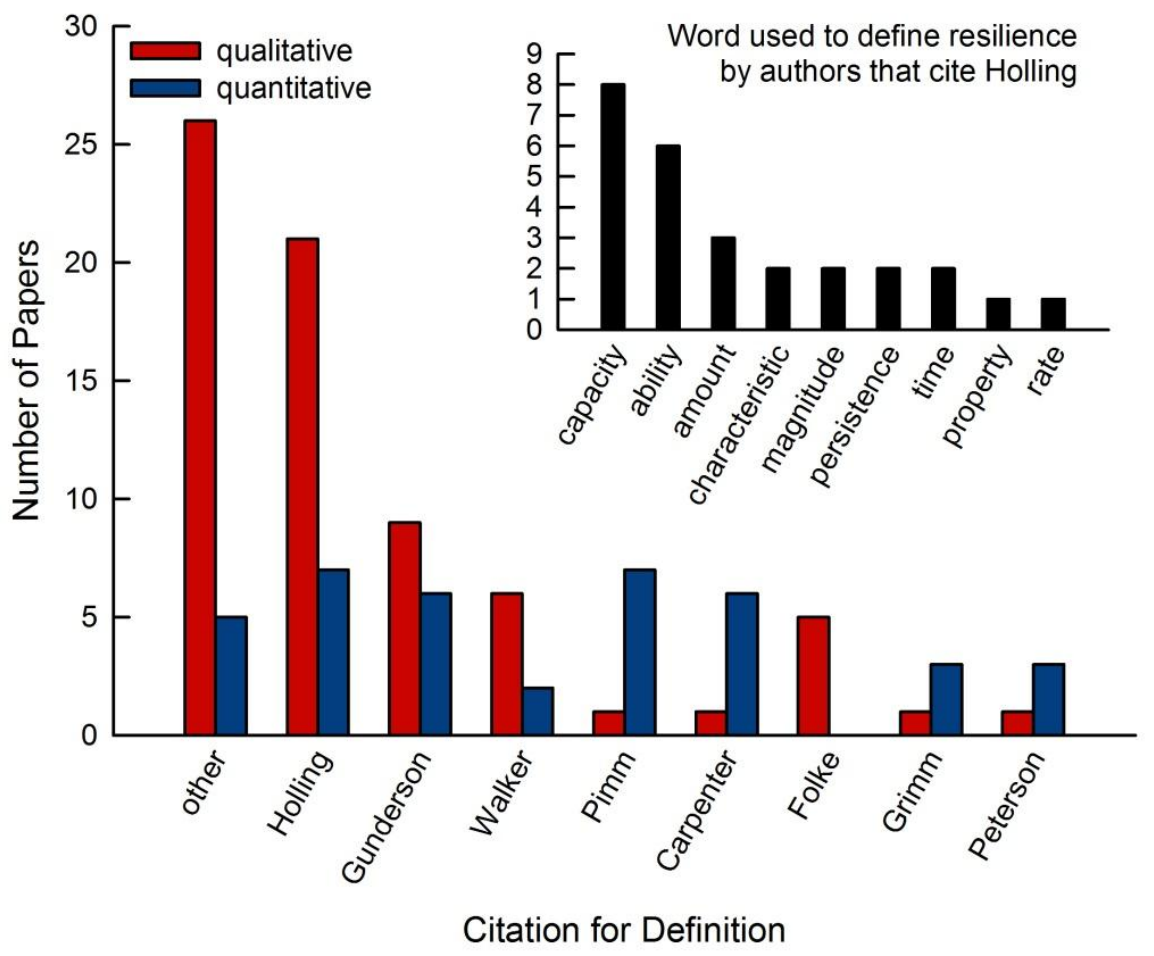

Figure 3. The number of papers with qualitative and quantitative definitions of resilience partitioned by the author cited. The inset plot shows the words used to define resilience by authors that cite Holling.

many definitions and citations found in our literature survey. For the most common quantitative definitions, we found a variety of citations given. In $7 \%$ of studies, resilience was defined as "the time, rate or speed for a system to recover from a given disturbance" (attributed citations: Holling 1973, Webster et al. 1975, Ewel 1980, Pimm 1984, Westman 1985, Pimm 1991, Holling 1996, Grimm and Wissel 1997, Peterson et al. 1998, Gunderson 2000, Carpenter et al. 2001, Gunderson and Holling, 2001, Hughes et al. 2003, and Suding et al. 2004). In $4 \%$ of studies, resilience was defined as "the magnitude, amount or degree of disturbance from which a system is able to recover to the original state" (attributed citations: Holling 1973, Walker 1981, Pimm 1984, Gunderson 2000, Nyström et al. 2000, Carpenter et al. 2001, Gunderson and Holling 2001, Walker et al. 2002, Gunderson 2002, and Folke et al. 2004). However, neither of these definitions is suitable for quantifying responses to ongoing (press) disturbances, such as climate change (Glasby and Underwood 1996), as were under investigation in $31 \%$ of the studies in our literature review. In fact, $21 \%$ of studies that used any of the above definitions were investigating press disturbances, indicating that in many studies there is a discrepancy between the definition given and the potential real-word application.

Often missing from the papers that we surveyed is reference to the comparative nature of the term. If a coral reef, salmon fishery or elephant population was described as having "low resilience", for example, we were left wondering whether the low resilience is relative to historic conditions, other similar study systems, or indeed other ecological systems altogether. In recent studies of resilience, different metrics have been used, ranging from the composition of a particular taxonomic group (Kennedy et al. 2003, Vinebrooke et al. 2003, Knapp et al. 2005, Watanabe et al. 2005, Wertz et al. 2007, Mitchell et al. 2009) or traits of a particular species (Isaac et al. 2009), to measuring an ecosystem function, such as soil respiration (Orwin and Wardle 2004) or plant productivity (DeClerck et al. 2006, Shinoda et al. 2010). These studies investigated different types of perturbations: drought (Kennedy et al. 2003, Orwin and Wardle 2004, DeClerck et al. 2006, Shinoda et al. 2010), lake acidification (Vinebrooke et al. 2003), sedimentation (Watanabe et al. 2005), heating (Wertz et al. 2007), fire (Mitchell et al. 2009) or loss of a top predator (Knapp et al. 2005). Resilience indices have 


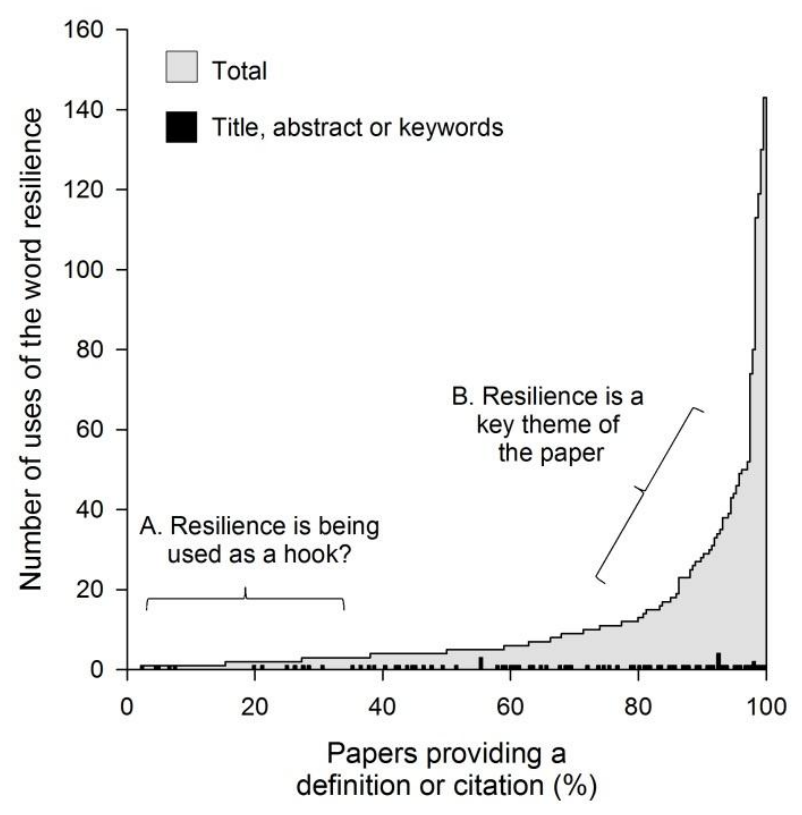

Figure 4. The total number of uses of the word resilience (grey) and the number of uses in the title, abstract or keywords (black) for papers that provided a definition or citation for resilience $(n=96)$. If a definition or citation is provided in the body of the paper, the use of resilience is most likely deemed by the author to be relevant to the study. If resilience is used in the title, abstract or keywords, and then not used more than a couple of times in the body of the paper (A), the term is potentially being used as a hook to attract a wider audience rather than being a key theme (B).

been proposed as a means to compare ecosystems (Steinman et al. 1991, Schmid 1992, Cole 1995, Littlemore and Barker 2001, Pérez-España and Arreguín-Sánchez 2001, Gallet and Rozé 2002, Lu and Li 2003, Orwin and Wardle 2004, Roovers et al. 2004, Watanabe et al. 2005, Wada and Toyota 2006, Fischer et al. 2007, Price et al. 2007, Isaac et al. 2009, Shinoda et al. 2010). These indices most often focus on the resilience of one ecosystem parameter or are specific to the study system, and none have been widely adopted in the ecological literature. Though such comparisons are currently rare, there may be ways to make quantitative comparisons of resilience among studies, taxa, disturbances or ecosystems.

In order to improve the understanding of resilience in the ecological literature, we believe that authors should refrain from using the term without definition, quantification or explanation, as is the case for approximately two thirds of the studies we reviewed. Given that multiple definitions of the term persist in the literature, authors should define how they are using the term and how it refers specifically to their study system.
Although use of a theoretical term may hook a wider audience, if it is used vaguely or imprecisely, this limits interpretation of the study and the potential for crossstudy comparisons. We believe that further progress in the application of resilience will only be made if the concept is systematically tested in experimental settings using real-world data. Greater precision in the use and quantification of resilience will promote the application of this concept beyond the ecological literature to the management and conservation of ecosystems.

\section{Acknowledgements}

We thank J. H. Myers, C. J. Krebs, C. C. St. Clair, and J. M. G. Hudson for valuable comments on the manuscript and the fall 2006 University of Alberta Advanced Ecology Class for stimulating this review. We also thank our reviewers B. Beisner and B. Starzomski for their thoughtful commentaries that expand and advance the discussion.

\section{Referees}

Beatrix E. Beisner - beisner.beatrix@uqam.ca

University of Quebec at Montreal

Brian Starzomski - starom@uvic.ca

University of Victoria

\section{References}

Botton, S., van Heusden, M., Parsons, J.R., Smidt, H. and N. van Straalen. 2006. Resilience of microbial systems towards disturbances. Critical Reviews in Microbiology 32:101-212. $\underline{\text { CrossRef }}$

Carpenter, S.R., Kraft, C.E., Wright, R., He, X., Soranno, P.A. and J.R. Hodgson. 1992. Resilience and resistance of a lake phosphorus cycle before and after food web manipulation. American Naturalist 140:781-798. CrossRef

Carpenter, S.R., Walker, B., Anderies, J.M. and N. Abel. 2001. From metaphor to measurement: resilience of what to what? Ecosystems 4:765-781. CrossRef

Cole, D.N. 1995. Experimental trampling of vegetation. 2. Predictors of resistance and resilience. Journal of Applied Ecology 32:215-224. CrossRef

Cumming, G.S., Barnes, G., Perz, S., Schmink, M., Sieving, K.E., Southworth, J., et al. 2005. An exploratory framework for the empirical measurement of resilience. Ecosystems 8:975-987. CrossRef

DeClerck, F.A.J., Barbour, M.G. and J.O. Sawyer. 2006. Species richness and stand stability in conifer forests of the Sierra Nevada. Ecology 87:2787-2799. CrossRef 
Fischer, J., Lindenmayer, D.B., Blomberg, S.P., Montague-Drake, R., Felton, A. and J.A. Stein. 2007. Functional richness and relative resilience of bird communities in regions with different land use intensities. Ecosystems 10:964-974. CrossRef

Folke, C., S. Carpenter, B. Walker, M. Scheffer, T. Elmqvist, L. Gunderson, and C. S. Holling. 2004. Regime shifts, resilience, and biodiversity in ecosystem management. Annual Review of Ecology, Evolution, and Systematics:557-581. CrossRef

Folke, C. 2006. Resilience: The emergence of a perspective for social-ecological systems analyses. Global Environmental Change 16:253-267. CrossRef

Gallet, S. and F. Rozé. 2002. Long-term effects of trampling on Atlantic heathland in Brittany (France): resilience and tolerance in relation to season and meteorological conditions. Biological Conservation 103:267-275. CrossRef

Glasby, T.M. and A.J. Underwood. 1996. Sampling to differentiate between pulse and press perturbations. Environmental Monitoring and Assessment 42:241252. CrossRef

Grimm, V. and C. Wissel. 1997. Babel, or the ecological stability discussions: An inventory and analysis of terminology and a guide for avoiding confusion. Oecologia 109:323-334. CrossRef

Gunderson, L. 2000. Ecological resilience-in theory and application. Annual Review of Ecology and Systematics 31:425-439. CrossRef

Holling, C.S. 1973. Resilience and stability of ecological systems. Annual Review of Ecology and Systematics 4:1-23. CrossRef

Holling, C.S. 1996. Engineering resilience vs. ecological resilience. Pages 31-44 in P.C. Schulze, editor. Engineering within Ecological Constraints. National Academy Press, Washington, D.C., USA.

Isaac, J.L., Vanderwal, J., Johnson, C.N. and S.E. Williams. 2009. Resistance and resilience: quantifying relative extinction risk in a diverse assemblage of Australian tropical rainforest vertebrates. Diversity and Distributions 15:280-288. CrossRef

Kennedy, A.D., Biggs, H. and N. Zambatis. 2003. Relationship between grass species richness and ecosystem stability in Kruger National Park, South Africa. African Journal of Ecology 41:131-140. CrossRef

Knapp, R.A., Hawkins, C.P., Ladau, J. and J.G. McClory. 2005. Fauna of Yosemite National Park lakes has low resistance but high resilience to fish introductions. Ecological Applications 15:835-847. CrossRef

Littlemore, J. and S. Barker. 2001. The ecological response of forest ground flora and soils to experimental trampling in British urban woodlands. Urban Ecosystems 5:257-276. CrossRef
Lu, F and Z. Li. 2003. A model of ecosystem health and its application. Ecological Modelling 170:55-59. CrossRef

MacArthur, R. 1955. Fluctuations of animal populations, and a measure of community stability. Ecology 36:533-536. CrossRef

Mitchell, R.J., Simonson, W., Flegg, L.A., Santos, P. and J. Hall. 2009. A comparison of the resilience of four habitats to fire, and the implications of changes in community composition for conservation: a case study from the Serra de Monchique, Portugal. Plant Ecology and Diversity 2:45-56. CrossRef

Orwin, K.H. and D.A. Wardle. 2004. New indices for quantifying the resistance and resilience of soil biota to exogenous disturbances. Soil Biology and Biochemistry 36:1907-1912. CrossRef

Pérez-España, H. and F. Arreguín-Sánchez. 2001. An inverse relationship between stability and maturity in models of aquatic ecosystems. Ecological Modelling 145:189-196. CrossRef

Pickett, S.T.A., Cadenasso, M.L. and J.M. Grove. 2004. Resilient cities: meaning, models, and metaphor for integrating the ecological, socio-economic, and planning realms. Landscape and Urban Planning 69:369384. $\underline{\text { CrossRef }}$

Pimm, S.L. 1991. The Balance of Nature? Ecological Issues in the Conservation of Species and Communities. University of Chicago Press, Chicago, USA.

Price, A.R.G., Keeling, M.J. and I.N. Stewart. 2007. A robustness metric integrating spatial and temporal information: application to coral reefs exposed to local and regional disturbances. Marine Ecology Progress Series 331:101-108. CrossRef

Roovers, P., Verheyen, K., Hermy, M. and H. Gulinck. 2004. Experimental trampling and vegetation recovery in some forest and heathland communities. Applied Vegetation Science 7:111-118. CrossRef

Schmid, P.E. 1992. Community structure of larval Chironomidae (Diptera. in a backwater area of the River Danube). Freshwater Biology 27:151-167. CrossRef

Shinoda, M., Nachinshonhor, G.U. and M. Nemoto. 2010. Impact of drought on vegetation dynamics of the Mongolian steppe: A field experiment. Journal of Arid Environments 74: 63-69. CrossRef

Steinman, A.D., Mulholland, P.J., Palumbo, A.V., Flum, T.F. and D.L. DeAngelis. 1991. Resilience of lotic ecosystems to a light-elimination disturbance. Ecology 74:1299-1313. CrossRef

Vinebrooke, R.D., Graham, M.D., Findlay, D.L. and M.A. Turner. 2003. Resilience of epilithic algal assemblages in atmospherically and experimentally acidified boreal lakes. Ambio 32:196-202.

Walker, B., Holling, C.S., Carpenter, S. and A. Kinzig. 2004. Resilience, adaptability and transformability in social-ecological systems. Ecology and Society $9: 5$. 
Wada, S. and K. Toyota. 2006. Repeated applications of farmyard manure enhance resistance and resilience of soil biological functions against soil disinfection. Biology and Fertility of Soils 43:349-356. CrossRef

Watanabe, K., Yoshimura, C. and T. Omura. 2005. Stochastic model for recovery prediction of macroinvertebrates following a pulse-disturbance in river. Ecological Modelling 189:396-412. CrossRef

Wertz, S., Degrange, V., Prosser, J. I., Poly, F., Commeaux, C., Guillaumaud, N. and X. Le Roux. 2007. Decline of soil microbial diversity does not influence the resistance and resilience of key soil microbial functional groups following a model disturbance. Environmental Microbiology 9:22112219. CrossRef

\section{Response to Referees}

Our literature survey on the term resilience developed out of discussions in a graduate-level ecology class. As early career scientists trying to build an understanding of the ecological concept of resilience, we found wading into the literature to be a daunting task. Our literature searches were sidetracked by the multiple definitions of the term in the literature, and by papers that used the term resilience in their title, abstract or keywords without further detailed discussion of the concept. This led us to question how resilience is used in the ecological literature, and then how this use might be improved. Our review also re-stimulates discussion on the challenging tasks of quantifying, comparing, and testing resilience theory in real-world systems. We are grateful to the thoughtful comments and responses to our paper from our reviewers. We hope that the dialogue will continue and lead to the adoption of better practices regarding the use and application of resilience.

We found compelling evidence (Table R1) that confusion surrounding the use of the term resilience in the ecological literature continues, more than a decade after it was last highlighted (Grimm and Wissel, 1997). When resilience is used in an unclear or imprecise manner, or as a hook for a paper, the relevance of this concept to a particular study is difficult to grasp. If imprecise usage is common - as we found in our literature survey - the development of a general understanding of the concept of resilience to the field of ecology is impeded.

\section{Problems with multiple definitions}

Multiple definitions for resilience are prevalent in the ecological literature. Although potential benefits might be associated with the maintenance of multiple definitions of an ecological term, as highlighted by Starzomski (2012) and others (Hodges, 2008; Strunz, 2012), multiple existing definitions can also be confusing unless authors are careful to define their usage. We found that, despite multiple existing definitions, most studies do not define or provide a citation for a definition of resilience. This would not be concerning if many studies only made passing reference to the term. Instead, we found that often studies use resilience in the title, abstract or keywords, thereby implying that the term is a key concept in their study, and then failed to include a definition, citation or description of the specific application to their study (Table R1, Figure 4).

\section{A lack of precision}

Starzomski (2012) questions the need for precise definitions in ecology. In our opinion, greater precision in the use of a term does not necessarily mean that one definition becomes dominant. Instead, precision refers to whether terms are defined and described adequately in the context of the study. We agree that there is no imperative for rigidity in the use of ecological terms. However, we find that resilience, though progressing forward in theoretical investigations (see Beisner 2012), seems to continue to be used imprecisely in the ecological literature.

Starzomski (2012) discusses the scientific method and the need to gather data to support or reject hypotheses. If, as Starzomski suggests, a concept (or a hypothesis) is supported by continued observation and experimentation, the definition or definitions should become more refined over time. This progression has occurred with many ecological terms or concepts, including succession, community, disturbance, and competition (Pickett et al., 2004). Other terms that have been the subject of many discussions of definitions and metrics, such as connectivity (Calabrese and Fagan, 2004), habitat (Hall et al., 1997) and niche (Soberón, 2007), which are used as examples by Starzomski, have frequently been measured in experimental and observational studies. Unlike these terms, no widely accepted method for measuring ecological resilience exists.

Although resilience can be-as Starzomski (2012) states - a "seductively simple" concept, without precise definitions, its usefulness remains limited. Instead, by using specific and precise definitions, we are able to per-form rigorous, empirical tests that may allow us to support the quantitative and comparative application of this concept in real-world systems. Starzomski (2012: 54) states that "few studies experimentally test whether individual systems exhibit resilience... and as a consequence the term finds little support amongst experimental ecologists." As field-based experimental ecologists, we find this to be very concerning. Sinclair (1989) argued that ecological theories are discarded not because they fail critical tests, but rather because they are untestable. We suggest, that perhaps the lack of 
Table R1. Summary of the issues with the use of the term resilience as identified by our literature survey.

\begin{tabular}{llcc}
\hline Issue & Index & $\begin{array}{c}\text { \% of studies } \\
\text { surveyed }\end{array}$ & Solution \\
\hline Lack of precision & No definition provided & $66 \%$ & \\
& No citation provided & $71 \%$ & $\begin{array}{l}\text { Provide a clear, relevant definition } \\
\text { and appropriate citation }\end{array}$ \\
& No definition or citation provided & $60 \%$ & $\mathrm{n}=234$ \\
Used as a hook & $\begin{array}{l}\text { Used in the title, abstract, or } \\
\text { keywords and less than 3 times in } \\
\text { the body text when a definition or } \\
\text { citation is given }\end{array}$ & $38 \%$ & Describe how the term applies to the \\
& & $\mathrm{n}=94$ & specific study system \\
\hline
\end{tabular}

experimental tests of resilience is due to the fact that this concept is so difficult to quantify in real-world systems.

\section{Problems with not quantifying the term}

There are a variety of reasons why resilience has not followed the path of other ecological terms, with the foremost being the theoretical complexity and difficulty of real-world application (summarized by Beisner 2012). Starzomski points out that terms without simple mathematically-derived definitions are difficult to use precisely. Beisner (2012) highlights the historical reasons for the multiple definitions of this term that persist in this "heavily term-laden field". She states that a clear understanding of the historical use of the term resilience is necessary to "alleviate the confused use of the term" (Beisner 2012:57), and she suggests that different pathways of state transition in complex systems could lead to uncertainty as to how resilience should be measured quantitatively. She too advocates for consistent usage of this term and for a move toward trying to quantify this concept in ecological studies. She does point out, however, that a quantitative analysis of resilience using real-world ecosystems will be no simple undertaking.

\section{Press versus pulse disturbances}

As we relate stability theory back to the real world, a variety of questions arise. For example, some of the definitions of resilience refer to the return time of an ecosystem or ecosystem parameter after disturbance (Carpenter et al., 1992; Pimm, 1991). In our literature survey, $31 \%$ of studies using the term resilience were investigating press disturbances (e.g., climate change). This raises the question of whether the resilience of an ecosystem, using these definitions, can be measured in response to an ongoing (press) or intensifying disturbance. Answering such questions is beyond the scope of our literature survey; however, we believe that it is in exploring these questions and by tying together theory, observational, and experimental data, that we may improve the use and utility of the concept of resilience in the ecological literature.

\section{Conclusions}

We don't intend to criticize the potential importance or utility of the term resilience, but instead set out to explore its use. We believe that the widespread lack of clarity and precision that we found in our literature survey, and the shortage of experimental quantifications of resilience are hampering progress. To improve clarity authors should: 1) define and cite a definition for how they are using the term, and 2) describe what ecosystem parameter and disturbance are being investigated and at which spatial and temporal scale. We, like both Beisner (2012) and Starzomski (2012), are optimistic that by refining our use of the term resilience, we can improve utility of the concept to the field of ecology. Although a substantial challenge, we believe that resilience needs to be further tested empirically and quantitatively so that progress can be made in its application to the management and conservation of real-world ecosystems.

Beisner, B.E. 2012. The shifting states of resilience: Easier to define than to measure. Ideas in Ecology and Evolution 5: 57-62. CrossRef

Calabrese, J.M., and W.F. Fagan. 2004. A comparisonshopper's guide to connectivity metrics. Frontiers in Ecology and the Environment. 2:529-536. CrossRef

Carpenter, S.R., Kraft, C.E., Wright, R., He, X., Soranno, P.A. and J.R. Hodgson. 1992. Resilience and resistance of a lake phosphorus cycle before and after food web manipulation. American Naturalist 140:781-98. CrossRef

Grimm, V., and C. Wissel. 1997. Babel, or the ecological stability discussions: an inventory and 
analysis of terminology and a guide for avoiding confusion. Oecologia. 109:323-334. CrossRef

Hall, L.S., P.R. Krausman, and M.L. Morrison. 1997. The Habitat Concept and a Plea for Standard Terminology. Wildlife Society Bulletin. 25:173-182.

Hodges, K.E. 2008. Defining the problem: terminology and progress in ecology. Frontiers in Ecology and the Environment. 6:35-42. CrossRef

Pickett, S.T.A., M.L. Cadenasso, and J.M. Grove. 2004. Resilient cities: meaning, models, and metaphor for integrating the ecological, socio-economic, and planning realms. Landscape and Urban Planning. 69:369-384. CrossRef

Pimm, S.L. 1991. The balance of nature? Ecological issues in the conservation of species and communities. University of Chicago Press, Chicago, USA.
Sinclair, A.R.E. 1989. Population regulation in animals. In Ecological concepts: the contribution of ecology to an understanding of the natural world. J.M. Cherrett, editor. Blackwell Scientific Publications. 197-241.

Soberón, J. 2007. Grinnellian and Eltonian niches and geographic distributions of species. Ecology Letters. 10:1115-1123. CrossRef

Starzomski, B.M. 2012. Clarity, confusion, and idea refining in ecology. Ideas in Ecology and Evolution 5:54-56. CrossRef

Strunz, S. 2012. Is conceptual vagueness an asset? Arguments from philosophy of science applied to the concept of resilience. Ecological Economics. 76:112-118. CrossRef 